\title{
A Phenomenological Model for the Transport and Plugging of Aerosol through Stress Corrosion Cracks
}

\section{Spent Fuel and Waste Disposition}

\section{Prepared for}

US Department of Energy Spent Fuel and Waste Science and Technology Stylianos Chatzidakis, John Scaglione Oak Ridge National Laboratory

November 29, 2019 M3SF-20OR010207031 ORNL/SPR-2019/1413 

This report was prepared as an account of work sponsored by an agency of the United States Government. Neither the United States Government nor any agency thereof, nor any of their employees, makes any warranty, express or implied, or assumes any legal liability or responsibility for the accuracy, completeness, or usefulness of any information, apparatus, product, or process disclosed, or represents that its use would not infringe privately owned rights. Reference herein to any specific commercial product, process, or service by trade name, trademark, manufacturer, or otherwise, does not necessarily constitute or imply its endorsement, recommendation, or favoring by the United States Government or any agency thereof. The views and opinions of authors expressed herein do not necessarily state or reflect those of the United States Government or any agency thereof. 



\section{A Phenomenological Model for the Transport and Plugging of Aerosol Through Stress Corrosion Cracks}

\section{SUMMARY}

This report documents work performed under the Spent Fuel and Waste Disposition Campaign for the US Department of Energy Office of Nuclear Energy (DOE-NE). This work was performed to fulfill the Level 3 milestone M3SF-20OR010207031, "Development and validation of phenomenological model on aerosol transport and plugging through stress corrosion cracks," within work package SF-20OR01020703, "Stress Corrosion Cracking - ORNL."

Recent experimental evidence from Sandia National Laboratories (SNL) (2018) demonstrated partial microchannel plugging due to particulate deposition. As a direct consequence of this plugging, the accuracy of consequence assessments can be improved by accounting for the leak path deposition of aerosol in the source term. The filtration effect of microchannels such as cracks is relevant to the source term assessments. An important side effect of aerosol deposition in leak paths could be the plugging of the leak path.

This report summarizes progress through FY19 on the development of a phenomenological model of aerosol transport, deposition, and plugging through microchannels. The purpose of this work is to introduce a generic, reliable numerical model for predicting aerosol transport, deposition, and plugging in leak paths that are similar to stress corrosion cracks while accounting for potential plugging formation. This effort includes (i) development of a numerical model to analyze the various deposition processes in leak paths and to provide quantitative estimates of penetration factors, as well as an understanding of the variables that affect them, (ii) confirmation of model validity with theoretical and experimental data, and (iii) parametric analysis for different scenarios, including various particle sizes, pressures, and crack dimensions. This model could be used to improve the accuracy of consequence assessments, reducing the uncertainty of radiological consequence predictive analyses by accounting for the filtering effect of leak path aerosol deposition and plugging in the source term.

This report includes (i) an overview of main stress corrosion cracking characteristics, (ii) an overview of the developed numerical model to analyze the various deposition processes in leak paths, to provide quantitative estimates of penetration factors, and to gain an understanding of the variables that affect them, (iii) a summary of validation results and verification of the model's validity with recent experimental results from SNL and others, and (iv) a model application example. 
This page is intentionally left blank. 


\section{ACKNOWLEDGMENTS}

This research was sponsored by the Spent Fuel and Waste Science and Technology Program of the US Department of Energy (DOE) and was carried out at Oak Ridge National Laboratory (ORNL) under contract DE-AC05-00OR22725 with UT-Battelle, LLC.

This report was developed with significant contributions, expert input, and guidance from Charles Bryan, Sam Durbin, and Eric Lindgren at Sandia National Laboratories (SNL).

The author would like to thank Sylvia Saltzstein at SNL and John Scaglione at ORNL for providing guidance and support to this project, and Andrea Beatty at ORNL for administrative support. 
This page is intentionally left blank. 


\section{CONTENTS}

SUMMARY iii

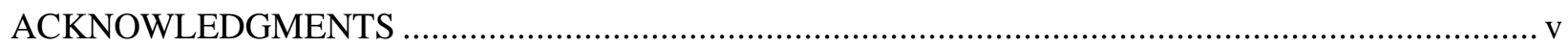



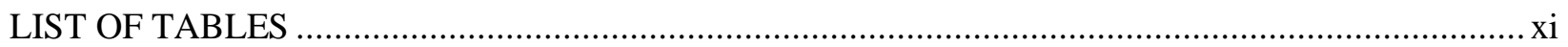

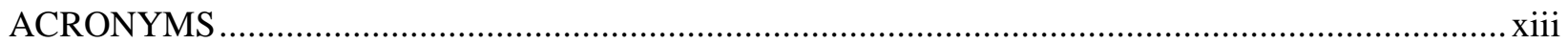

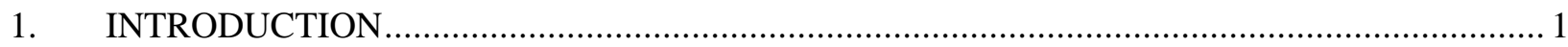

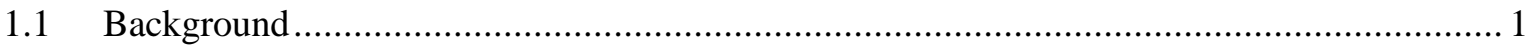

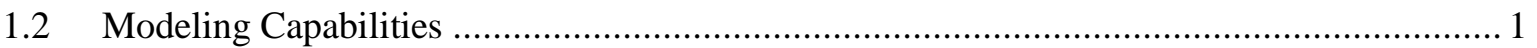

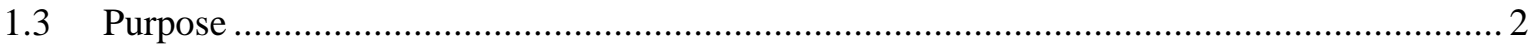



2.1 Stress Corrosion Cracking Characteristics............................................................. 4











2.1.6 Crack opening area and estimated leakage rate ................................................ 6

3. AEROSOL TRANSPORT AND PLUGGING MODEL …............................................. 7









3.1.5 Depressurization and Transient State ....................................................... 8

3.1.6 Aerosol Coagulation and Deposition within Canister...................................... 9







4.3 Comparison with Gelain and Vendel (2007) ............................................................ 14












This page is intentionally left blank. 


\section{LIST OF FIGURES}

Figure 1. Left: estimated surface temperatures over total storage time and illustration of potential SCC regime; right: crack opening displacement median, minimum, and maximum values.

Figure 2. Block diagram for numerical solution of the aerosol transport equation [Chatzidakis 2018b]. 10

Figure 3. Flow rate vs. pressure differential (pre-aerosol measurements)........................................... 11

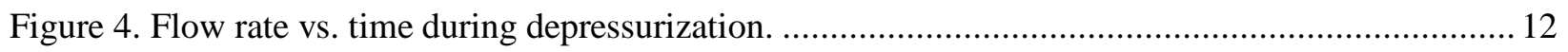

Figure 5. Upstream aerosol mass concentration as a function of time. ............................................. 12

Figure 6. Penetration fraction of particles as a function of particle diameter. ….................................. 13



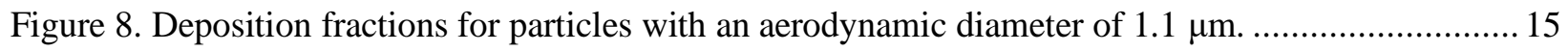

Figure 9. Aerosol concentration in container as a function of time. The aerosol reduction is due to coagulation. 16

Figure 10. Aerosol penetration efficiency vs. average flow velocity in capillaries............................... 16

Figure 11. Flow rate vs. pressure difference for rectangular geometry [Gelain and Vendel 2007]. .......... 17

Figure 12. Flow rate vs. pressure difference for cylindrical geometry [Sutter et al. 1979]. .................... 17

Figure 13. Penetration fraction as a function of particle diameter for crack heights $\mathrm{e}=30 \mu \mathrm{m}$ and $\Delta \mathrm{P}=50 \mathrm{~Pa}, 100 \mathrm{~Pa}$, and $200 \mathrm{~Pa}$.

Figure 14. Regimes for aerosol transport through CISCC as a function of pressure difference (Penetration as a function of the particle size spectrum is shown in upper right of figure; Ambient conditions: conditions following canister depressurization). 
This page is intentionally left blank. 


\section{LIST OF TABLES}

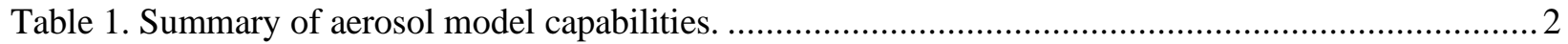

Table 2. Summary of aerosol tests in open literature and aerosol model validation status........................ 3

Table 3. Crack width at surface, midway, and at tip of intragranular (IG) SCC in austenitic stainless steels [SKI 2006]. .

Table 4. Crack surface roughness and grain size of IGSCC in austenitic stainless steels [SKI 2006]. 6

Table 5. Estimated leakage rate and time to depressurization for some DPCs [EPRI 2017]....................6 
This page is intentionally left blank. 
ACRONYMS

CISCC chloride-induced stress corrosion cracking

CFR US Code of Federal Regulations

DOE US Department of Energy

DPC dual-purpose canister

DSS dry storage system

EPRI Electric Power Research Institute

GDE general dynamic equation

IGSCC intragranular stress corrosion cracking

NWTRB US Nuclear Waste Technical Review Board

ORNL Oak Ridge National Laboratory

SCC stress corrosion cracking

SNL Sandia National Laboratories 
This page is intentionally left blank. 


\section{SPENT FUEL AND WASTE DISPOSITION PROGRAM A PHENOMENOLOGICAL MODEL FOR THE TRANSPORT AND PLUGGING OF AEROSOL THROUGH STRESS CORROSION CRACKS}

\section{INTRODUCTION}

Recent experimental evidence from Sandia National Laboratories (SNL) (2018) demonstrated partial microchannel plugging due to particulate deposition. As a direct consequence of this plugging, the accuracy of consequence assessments can be improved by accounting for the leak path deposition of aerosol in the source term. The filtration effect of such cracks is relevant to the source term assessments. An important side effect of aerosol deposition in leak paths could be the plugging of the leak path. Further research into this phenomenon is recommended.

\subsection{Background}

Modeling aerosol transport, retention, and plugging involves analysis of the thermohydraulic behavior of the canister and the microchannel/crack, as well as the geometric characteristics of the microchannel/crack and the aerosol features. The minimum set of parameters to be identified includes:

- Thermohydraulics: within this area, the most important parameters are the pressure inside the canister, the gas composition, the pressure drop, and the wall temperature along the crack.

- Crack geometry: the parameters to be considered are mainly the crack's path and its hydraulic diameter; information regarding the crack section's shape and curvature are also very important.

- Aerosol features: aerosol average composition, concentration, and size distribution are the reference parameters, while other parameters regarding aerosol morphology can be only considered with large uncertainties.

A compilation of available data in support of model development includes (i) canister characteristics such as pressure, temperature, heat load, environmental conditions, (ii) particle size distribution within the canister for various scenarios, (iii) crack characteristics such as size, opening, and roughness, and (iv) past models and experiments involving aerosol transport [Chatzidakis 2018a].

\subsection{Modeling Capabilities}

The proposed phenomenological model is based on the aerosol general dynamic equation and can simulate rough or smooth surfaces, irregular geometries, and unsteady flow. Four main deposition mechanisms - gravitation, Brownian diffusion, turbulent diffusion, and eddy impaction - have been included. Laminar, transition, and turbulent gas flow regimes have also been included in the model. The proposed model currently under development is being tested and compared with experimental and theoretical work to evaluate its validity and identify its range of applicability.

Particle size, distribution, pressure differential, flow regimes, and microchannel dimensions can be simulated using the current model. The model can predict pressure change over time due to depressurization (transient state) and particle deposition within a large vessel such as a canister, before, during, and after depressurization. A summary of the model's characteristics is presented in Table 1, and details of the model's current validation status are provided in Table 2. 


\section{A Phenomenological Model for the Transport and Plugging of Aerosol \\ Through Stress Corrosion Cracks}

\subsection{Purpose}

This report outlines a generic phenomenological model of aerosol transport, deposition, and plugging through microchannels. It includes (i) an overview of main stress corrosion cracking characteristics, (ii) an overview of the developed numerical model to analyze the various deposition processes in leak paths, to provide quantitative estimates of penetration factors, and to gain an understanding of the variables that affect them, (iii) a summary of validation results and verification of the model's validity with recent experimental results from SNL and others, and (iv) an application example.

Table 1. Summary of aerosol model capabilities.

\begin{tabular}{|l|l|}
\hline Particle diameter & $0.01-10 \mu \mathrm{m}$ \\
\hline Particle distribution & Monodisperse / polydisperse \\
\hline Pressure & $4 \mathrm{~Pa}-700 \mathrm{kPa}$ \\
\hline Microchannel dimensions & $5 \mu \mathrm{m}-1 \mathrm{~mm}$ \\
\hline Coagulation & Yes \\
\hline Deposition mechanisms & $\begin{array}{l}\text { Brownian diffusion, gravitation, turbulent diffusion, } \\
\text { inertia, thermophoresis }\end{array}$ \\
\hline Plugging & Yes \\
\hline Steady state & Yes \\
\hline Transient state & Yes \\
\hline Flow regimes & Laminar, transitional, turbulent \\
\hline Depressurization & Yes \\
\hline Fluid & Air, He \\
\hline
\end{tabular}


Table 2. Summary of aerosol tests in open literature and aerosol model validation status.

\begin{tabular}{|c|c|c|c|c|c|c|c|}
\hline Experiment & $\begin{array}{l}\text { Type of } \\
\text { test }\end{array}$ & Material & $\Delta \mathbf{P}$ & $\begin{array}{c}\text { Particle } \\
\text { diameter } \\
\text { (capillary) } \\
(\mu \mathrm{m})\end{array}$ & $\begin{array}{c}\text { Diameter } \\
\text { (or height } \times \text { width }) \\
\text { of slot or crack }\end{array}$ & Length (mm) & Validation status \\
\hline $\begin{array}{l}\text { Morton and Mitchell } \\
(1994)\end{array}$ & Capillary & $\mathrm{n} / \mathrm{a}$ & $20-80 \mathrm{kPa}$ & $1-10$ & $28-35 \mu \mathrm{m}$ & $19-21$ & Completed \\
\hline Lewis (1995) & Slot & $\mathrm{n} / \mathrm{a}$ & $10 \mathrm{kPa}$ & $1-6$ & $100 \mu \mathrm{m} \times 40 \mathrm{~mm}$ & $\mathrm{n} / \mathrm{a}$ & Completed \\
\hline Mosley et al. (2001) & Slot & Aluminum & $2-20 \mathrm{~Pa}$ & $0.05-5$ & $508 \mu \mathrm{m} \times 433 \mathrm{~mm}$ & 102 & Completed \\
\hline Liu and Nazaroff (2003) & Slot & Concrete & 4-10 Pa & $0.02-7$ & $0.25 \mathrm{~mm}, 1 \mathrm{~mm}$ & 45 & Completed \\
\hline $\begin{array}{l}\text { Gelain and Vendel } \\
(2007)\end{array}$ & Crack & Concrete & $0-12 \mathrm{kPa}$ & $0.8 ; 1.1 ; 4.1$ & $49.2 \mu \mathrm{m} \times 11.8 \mathrm{~m}$ & 100 & Completed \\
\hline Tian et al. (2017) & Capillary & Silica & $60-450 \mathrm{kPa}$ & $<0.3$ & $5-20 \mu \mathrm{m}$ & $10-80$ & Completed \\
\hline Lai et al. (2012) & Slot & Aluminum & 2-8 Pa & $20-500$ & $50 \times 250 \mathrm{~mm}$ & 90 & Completed \\
\hline $\begin{array}{l}\text { Nelson and Johnson } \\
(1975)\end{array}$ & Capillary & $\mathrm{n} / \mathrm{a}$ & $3 \mathrm{kPa}$ & $3-5$ & $520 \mu \mathrm{m}, 1,070 \mu \mathrm{m}$ & $40-80$ & In progress \\
\hline SNL (2018) & Slot & Steel & $700 \mathrm{kPa}$ & 1 & $28.9 \mu \mathrm{m} \times 8.86 \mathrm{~mm}$ & 12.7 & In progress \\
\hline
\end{tabular}




\section{OVERVIEW}

This section presents an overview of publicly available data on stress corrosion cracking characteristics, including shape, roughness, opening displacement, and estimated leakage rate. The currently available data are used as a starting point for the development of gas flow and aerosol leakage models. Additional details and compilation of available data in the open literature on canister characteristics such as pressure, temperature, heat load, and environmental conditions, as well as and past models and experiments involving aerosol transport, can be found in the literature review by Chatzidakis [Chatzidakis 2018a].

\subsection{Stress Corrosion Cracking Characteristics}

Stress corrosion cracking (SCC) is a localized degradation process that can initiate cracks by the combined actions of residual or applied stress and electrochemical corrosion. Three factors are necessary for SCC to occur: tensile stress, aggressive electrolyte, and susceptible material. Cracks are most likely to start in the zones affected by weld heat or in crevices in the canister's surface. The tendency for cracking depends on temperature, relative humidity, time of exposure, and chemistry. After a few decades of storage, canister surface temperatures are in the regime for corrosion-induced degradation (Figure 1). However, cracking can occur at higher temperatures if conditions allow deliquescence of corrosion agents.

Most intergranular SCC develops next to welds, with straight or winding cracks oriented almost parallel to the weld. Single cracking is most common, but occasionally, two cracks will form on each side of the weld. In the through thickness direction, intergranular-SCC is typically winding, or lightly bending, and macroscopic branching is rare. The surface roughness is normally on a grain size magnitude, and the cracks are particularly narrow if secondary corrosion is small.
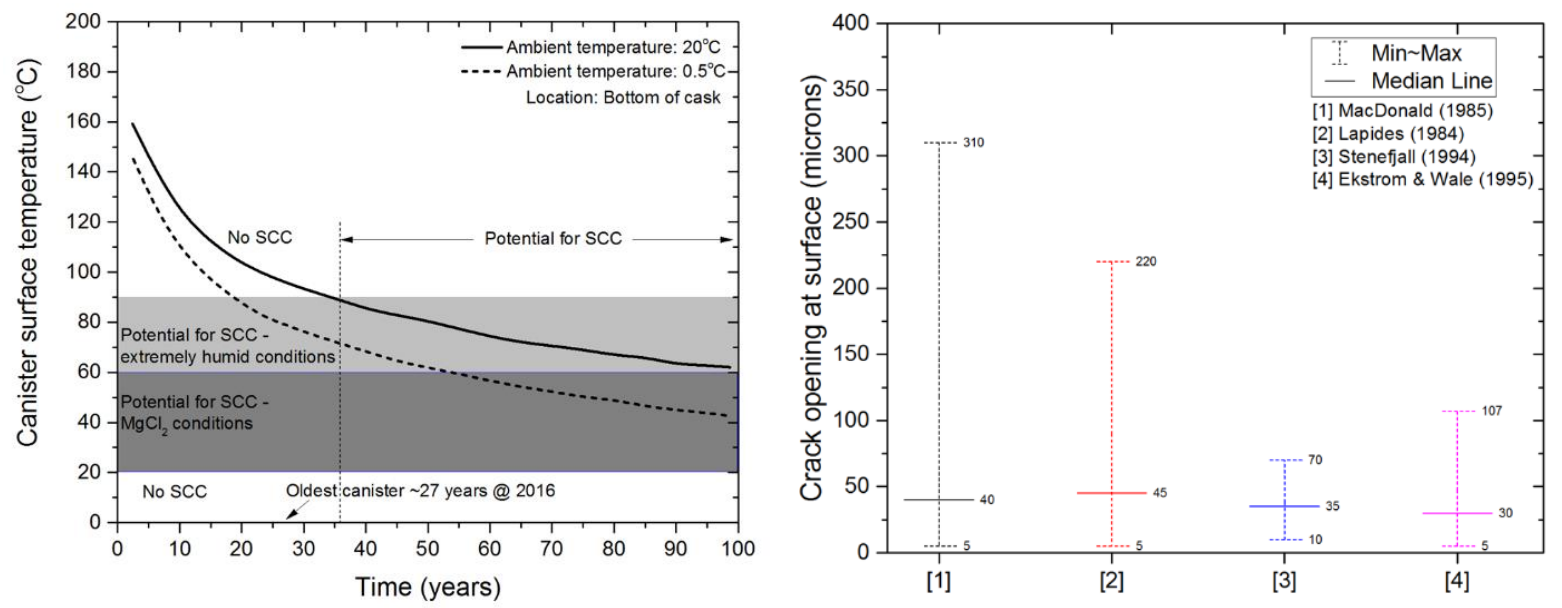

Figure 1. Left: estimated surface temperatures over total storage time and illustration of potential SCC regime; right: crack opening displacement median, minimum, and maximum values.

\subsubsection{Crack opening and width}

Experiments have shown that SCC exhibits crack opening displacements of 15-30 $\mu \mathrm{m}$ (Figure 1). Crack width midway between the surface and the crack tip is smaller. Crack width at the crap tip is on the order of $1 \mu \mathrm{m}$. Table 3 shows statistics from 65 cracks, including crack width at the surface, midway, and at the tip. These statistics show that the crack width decreases further from the surface. 
Table 3. Crack width at surface, midway, and at tip of intragranular (IG) SCC in austenitic stainless steels [SKI 2006].

\begin{tabular}{|l|c|c|c|}
\hline & $\begin{array}{c}\text { Crack width at } \\
\text { surface }(\boldsymbol{\mu m})\end{array}$ & $\begin{array}{c}\text { Crack width at } \\
\text { midway }(\boldsymbol{\mu m})\end{array}$ & $\begin{array}{c}\text { Crack width at tip } \\
(\boldsymbol{\mu m})\end{array}$ \\
\hline Min & 3 & 2 & 1 \\
\hline Max & 160 & 133 & 25 \\
\hline Mean & 37.7 & 22.5 & 4.7 \\
\hline Median & 30 & 16 & 3 \\
\hline $\begin{array}{l}\text { Standard } \\
\text { deviation }\end{array}$ & 28.7 & 22.0 & 4.74 \\
\hline
\end{tabular}

\subsubsection{Orientation}

Due to maximum sensitization, the cracks are typically are oriented parallel to welds and are located in the heat-affected zone (HAZ). Cracks are expected to form in the regions of most severe sensitization. Thus, the distance between the crack and the weld fusion line depends on the welding parameters, the number of weld beads, wall thickness, etc. Furthermore, heat input is a crucial parameter. The typical distance between the crack and the weld fusion line found in this work is between 0 and $10 \mathrm{~mm}$. For single run welding, the distance may be calculated. However, determining the distance for multi-run welding is more complicated, and maximum sensitization may occur very close to the root run fusion line, because the second weld run may sensitize the root run's HAZ.

\subsubsection{Shape}

The typical shape in surface direction is straight or winding. Most cases showed a continuous crack running at a relatively constant distance from the weld. However, there are exceptions showing discontinuous cracking, as well as cracks growing at various distances from weld.

\subsubsection{Location}

Recently, a welded, Type 304L stainless steel coupon test was conducted as part of a qualification program for plutonium storage containers that developed SSC when exposed to salt mixtures containing only about $0.6 \mathrm{wt} \%$ moisture at room temperature. The SCC initiated in the HAZ of the weld and propagated along the HAZ and into the base metal. These observations are clearly relevant to the welded canisters placed in dry storage. The number of cracks is typically one, but up to six separate cracks have been observed. The orientation in the thickness direction is typically $90^{\circ}$, but cracks tend to be towards the weld metal. The typical shape of the cracks in the through thickness direction is winding due to the intergranular growth. Curved cracks are common, and crack growth tends to turn towards the weld. Crack growth into the weld metal is very unusual.

\subsubsection{Roughness}

Surface roughness of the cracks has been evaluated from crack profiles derived from micrographs. It was found that the surface roughness is strongly influenced by the grain size. Table 4 shows surface roughness and grain size statistics derived from 69 crack measurements. Surface roughness is on the order of grain size. These results show that surface roughness varies from 8 to $200 \mu \mathrm{m}$, with a median value of $68 \mu \mathrm{m}$. The grain size varies from 15 to $250 \mu \mathrm{m}$, with a median value of $50 \mu \mathrm{m}$. 
Table 4. Crack surface roughness and grain size of IGSCC in austenitic stainless steels [SKI 2006].

\begin{tabular}{|l|c|c|}
\hline & Surface roughness $(\boldsymbol{\mu m})$ & Grain size $(\boldsymbol{\mu m})$ \\
\hline Min & 8 & 15 \\
\hline Max & 200 & 250 \\
\hline Mean & 70.7 & 69.6 \\
\hline Median & 68 & 50 \\
\hline Standard deviation & 39.6 & 51.9 \\
\hline
\end{tabular}

\subsubsection{Crack opening area and estimated leakage rate}

Typical values the width of the crack opening area vary from 0.004 to $0.025 \mathrm{~cm}^{2}$ based on a crack length of $2.5 \mathrm{~cm}$. Estimated leakage rates and exchange times needed to replace the helium in a canister with air for a variety of cases in which parameters - including the canister internal free volume and the chlorideinduced stress corrosion cracking (CISCC) opening area-are shown in Table 5. The estimates assume a single through-wall crack. Pressurization is calculated to dissipate within one day for all canister designs when assuming a crack opening area of $0.025 \mathrm{~cm}^{2}$. Cases with a crack opening area of $0.004 \mathrm{~cm}^{2}$ required longer, up to 52 days. The values shown are maximum leak rate values. The leakage rate decays with time as the pressurization decreases.

Table 5. Estimated leakage rate and time to depressurization for some DPCs [EPRI 2017].

\begin{tabular}{|l|c|c|c|c|c|}
\hline \multicolumn{1}{|c|}{ Cask model } & $\begin{array}{c}\text { Canister } \\
\left.\text { volume } \mathbf{( c m}^{\mathbf{3}}\right)\end{array}$ & $\begin{array}{c}\text { Initial } \\
\text { pressure } \\
(\mathbf{M P a})\end{array}$ & $\begin{array}{c}\text { Crack } \\
\text { opening } \\
\text { area }\left(\mathbf{c m}^{\mathbf{2}}\right)\end{array}$ & $\begin{array}{c}\text { Leakage } \\
\text { rate }\left(\mathbf{c m}^{\mathbf{3}} \mathbf{s}\right)\end{array}$ & $\begin{array}{c}\text { Time to } \\
\text { depressurizatio } \\
\text { n }(\mathbf{d a y s})\end{array}$ \\
\hline HI-STORM 24 & $6.76 \mathrm{E} 6$ & 0.69 & 0.025 & 943 & 1 \\
\hline NUHOMS 32PT & $3.77 \mathrm{E} 6$ & 0.10 & 0.025 & 484 & 1 \\
\hline UMS 24 & $5.74 \mathrm{E} 6$ & 0.10 & 0.025 & 431 & 1 \\
\hline MAGNASTOR 37 & $6.56 \mathrm{E} 6$ & 0.76 & 0.025 & 960 & 52 \\
\hline HI-STORM 24 & $6.76 \mathrm{E} 6$ & 0.69 & 0.004 & 28.7 & 52 \\
\hline NUHOMS 32PT & $3.77 \mathrm{E} 6$ & 0.10 & 0.004 & 4.44 & 52 \\
\hline
\end{tabular}




\section{AEROSOL TRANSPORT AND PLUGGING MODEL}

This section presents an overview of the phenomenological aerosol transport and plugging model. The model is described in more detail in summaries by Chatzidakis [Chatzidakis 2018b and Chatzidakis 2019]; only the main features are summarized in this section. Overall, the model can predict important quantities such as plug mass, gas passed, plugging time, plug profile, and aerosol penetration or retained fraction.

\subsubsection{Aerosol Transport Equation}

The behavior of an aerosol within a volume may change due to internal processes that occur within the volume, and external processes that transport particles across the volume boundaries. Internal processes include coagulation, agglomeration, fragmentation, and gas-to-particle conversions. External processes include transport across the boundaries due to gas flow, diffusion, particle motion as a result of temperature gradients, concentration gradients, gravitational settling, and other external forces. All processes are described by a balance equation that is known as the general dynamic equation (GDE).

The GDE for the case of aerosol penetration through a microchannel assuming only external processes is reduced to a transport equation, which can be written as follows in one-dimensional form [Mitrakos et al. 2008, Chatzidakis and Scaglione 2019]:

$$
\frac{\mathrm{dC}(\mathrm{x}, \mathrm{t})}{\mathrm{dt}}+\frac{1}{A(\mathrm{x}, \mathrm{t})} \frac{d}{d x}[A(\mathrm{x}, \mathrm{t}) \cdot u(\mathrm{x}, \mathrm{t}) \cdot C(\mathrm{x}, \mathrm{t})]=-\mathrm{V}_{d}(\mathrm{x}, \mathrm{t}) \frac{\chi(\mathrm{x}, \mathrm{t})}{A(\mathrm{x}, \mathrm{t})} C(\mathrm{x}, \mathrm{t}),
$$

where $C$ is the aerosol mass concentration, $V_{d}$ is the deposition velocity, $A$ is the cross-sectional area, $\chi$ is the wetted perimeter of the cross section, and $u$ is the gas velocity. All previous parameters are functions of the axial coordinate $x$ and time $t$. The deposition velocity is calculated as the sum of the deposition velocities corresponding to each individual deposition mechanism: gravitation, diffusion, etc.

\subsubsection{Flowrate}

The aerosol transport equation given above can be applied to any cross sectional shape for which the hydraulic diameter and mass flow rate are known. The mass flow rate $\mathrm{Q}_{\mathrm{m}}$ can be written as a function of the pressure drop along the flow direction (Williams 1994):

$$
p_{u}^{2}-\mathrm{p}_{d}^{2}=\mathrm{R}_{g} \mathrm{TQ}_{m}^{2} \int_{0}^{L} C_{f}(\mathrm{Re}) \frac{\chi(x)}{A^{3}(x)} \mathrm{dx},
$$

where $x$ is the axial distance from the inlet of the crack (or capillary), $p_{u}$ is the pressure at the upstream of the crack, $p_{d}$ is the pressure at the downstream of the crack, $L$ is the length of the duct, $\chi$ is the perimeter of the duct, and $A$ is the cross sectional area. This equation can be solved numerically to determine the mass flow rate $Q_{m}$. When this is known, the velocity and volume flow rate can be calculated using mass continuity.

\subsubsection{Deposition Mechanisms}

Deposition mechanisms transport aerosol to the walls of a leak path due to gas flow, gradients, or external forces. Four deposition mechanics are considered herein: gravitational settling, Brownian diffusion, inertial impaction, and eddy impaction for the case of turbulent flow conditions. These deposition mechanisms play a crucial role in aerosol retention within a microchannel and are described in more detail in a Chatzidakis' summary [Chatzidakis 2018b]. Other deposition mechanisms such as electrophoresis and diffusiophoresis are neglected, as rough calculations indicate that these mechanisms are relatively unimportant in the removal of particles in leak paths for conditions relevant to stress corrosion cracks. 


\subsubsection{Plugging}

A leak path through which aerosol passes and is deposited may become partially or completely plugged.

The particulate matter will deposit on the surface, changing the internal geometry of the flow area.

Eventually the plug mass will increase, leading to complete obstruction of the pathway.

The mass of the deposit up to any position $\mathrm{S}$ can be obtained in terms of the deposition velocity and the particle concentration, as follows:

$$
M_{d e p}=\int_{0}^{S} \int_{0}^{t} 2 \pi R C V_{d} d x d t .
$$

Assuming that the deposit material is homogeneous with a density equal to the density of the particles, the volume of the deposit can be directly derived from its mass:

$$
V_{d e p}=\frac{M_{d e p}}{\rho_{p}} .
$$

In Eq. (4) above, density $\rho_{p}$ is assumed to be the bulk material density. This approximation is more accurate for large particles that are deposited mainly by gravity or eddy impaction. The deposition of particles is assumed to occur uniformly on the path's circumference. This assumption is valid for mechanisms such as Brownian or turbulent diffusion or for eddy impaction, but it is approximate for directional mechanisms such as gravitational settling. Under this assumption, the change in radius due to plugging is related to the deposit volume, as follows:

$$
d R=\frac{1}{2 \pi R} \frac{d V_{d e p}}{d x} .
$$

The aerosol transport equation, Eq. (1), is solved using an implicit finite difference scheme. The upwind scheme is used for the discretization of the convection term, which is the second term on the left-hand side of Eq. (1). The duct radius is then updated according to Eq. (2) by calculating the amount of the deposited mass as shown in Eqs. (3) and (4). All the numerical integrations required in this calculation are performed using the trapezoidal rule. The new cross section is then used for the aerosol calculations in the next step (Figure 2).

\subsubsection{Depressurization and Transient State}

The model described above assumes deposition only within a microchannel under constant (steady state) conditions; it does not account for any depressurization events that may influence deposition. To address these shortcomings, a depressurization equation was added to the model to account for pressure change over time (transient state). Furthermore, the model was extended to account for coagulation and deposition within a vessel such as a canister, with dimensions much larger than that of a microchannel. With these enhancements, aerosol reduction due to coagulation and deposition mechanisms within a large vessel and within a microchannel can be predicted before, during, and after depressurization.

Combining mass and energy conservation equations for vessel depressurization, one can arrive at the following formula:

$$
\frac{d P_{\text {vessel }}}{d t}=-\frac{Q_{m} P_{\text {vessel }} \gamma_{g}}{M_{\text {vessel }}}
$$

where $\gamma_{g}$ is the ratio of specific heat capacity at constant pressure and volume. Applying the forward Euler method (explicit) to iterate pressure over time, it is possible to follow the pressure changes in the system to determine the time when pressures will equalize. 


\subsubsection{Aerosol Coagulation and Deposition within Canister}

The principle of mass conservation when applied to aerosol particles inside a canister is:

$$
\frac{d C_{1}}{d t}=-K_{1 c} C_{1}^{2}-\frac{Q(t) C_{1}}{V_{1}}-\left(K_{1 g}+K_{1 d}\right) C_{1}
$$

where $K_{l c}$ is the coagulation decay rate, $C_{l}$ is the particle concentration, $t$ is time, $Q$ is the volumetric flowrate, $V_{l}$ is the canister's free volume, $K_{l g}$ is the particle decay rate due to gravitational settling, and $K_{l d}$ is the particle decay rate due to diffusion to the surfaces. The first and second terms on the right side represent the rate at which particles are removed from the canister by coagulation and airflow. The third term represents the rate at which particles are removed by deposition mechanisms on surfaces other than a microchannel. 


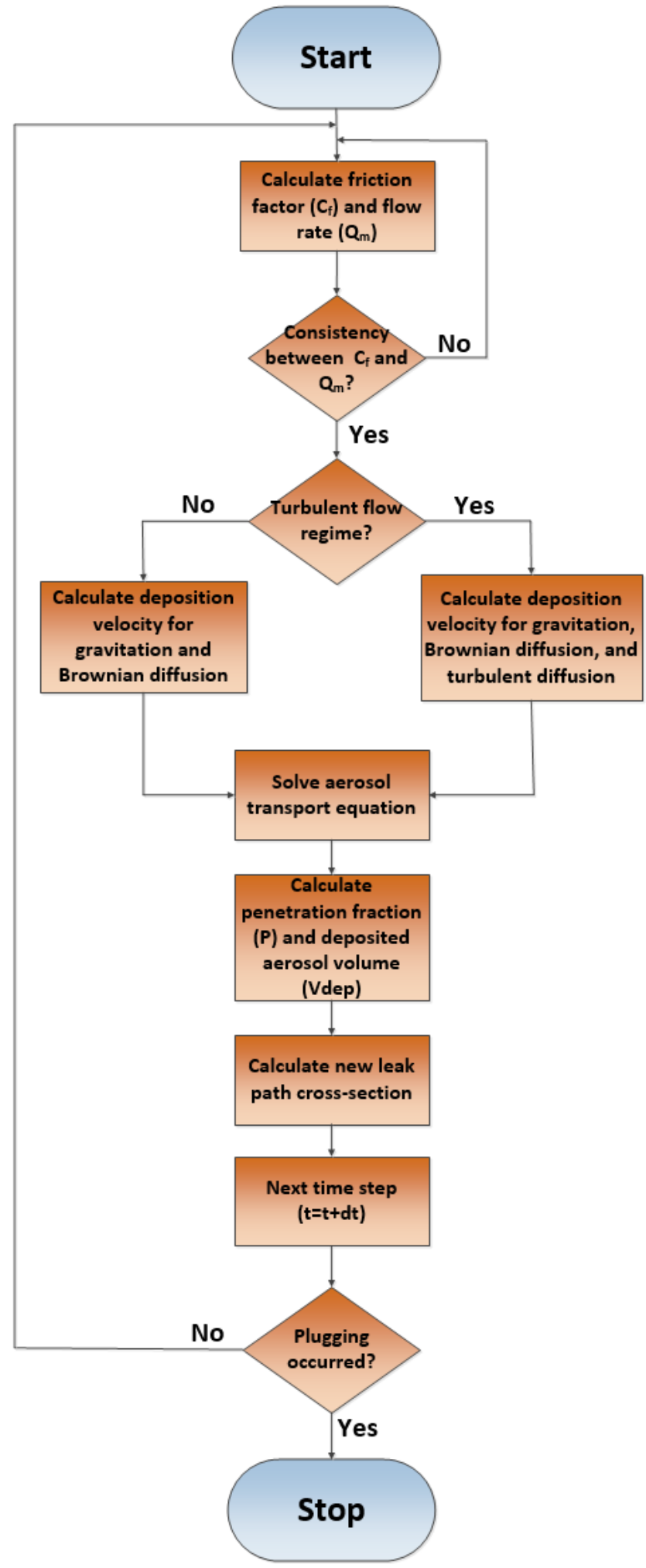

Figure 2. Block diagram for numerical solution of the aerosol transport equation [Chatzidakis 2018b]. 


\section{A Phenomenological Model for the Transport and Plugging of Aerosol Through Stress Corrosion Cracks}

\section{VALIDATION RESULTS}

To evaluate the proposed aerosol transport and plugging model, the model described in Section 3 was benchmarked against real experimental cases of particle penetration and plugging in leak paths under a variety of conditions in tubes, slots, or real cracks. Four distinctive, independent types of experiments are presented. The first is based on recent SNL measurements made on microchannels [Sandia 2018]. The second and third experiments are focused on penetration of particles through the cracks of a naturally broken brick [Liu and Nazaroff 2003] and on penetration of particles through a cracked reinforced concrete sample [Gelain and Vendel 2007]. The fourth experiment focuses on penetration of particles through microcapillaries [Tian et al. 2017]. The validation results are described in more detail in Chatzidakis' Summary of Aerosol Transport Model Validation [Chatzidakis 2019]; only the main results are summarized in this section.

\subsection{Comparison with Sandia Experiments (2018)}

The results of the present model vs. SNL's experimental measurements are shown in Figure 3. The measurements were taken before aerosol was released into the tank, so there was no aerosol influence (pre-aerosol measurements). Good agreement is observed with experimental measurements.

The following observations are made:

- A flow rate based on the laminar friction factor significantly overestimates the flow rate. It can be inferred that the flow is not laminar, despite the Reynolds number being less than 2,300.

- The friction factor correlation of Gelain (Gelain 2007) - which captures the laminar to turbulent transition region at $\mathrm{Re}=5-10$ and was developed based on experimental data from concrete cracks - underestimates the flow rate.

- Trials with different friction factor correlations were performed, but none successfully reproduced the experimental measurements.

- A new friction factor correlation is needed to capture the measured flow rate.

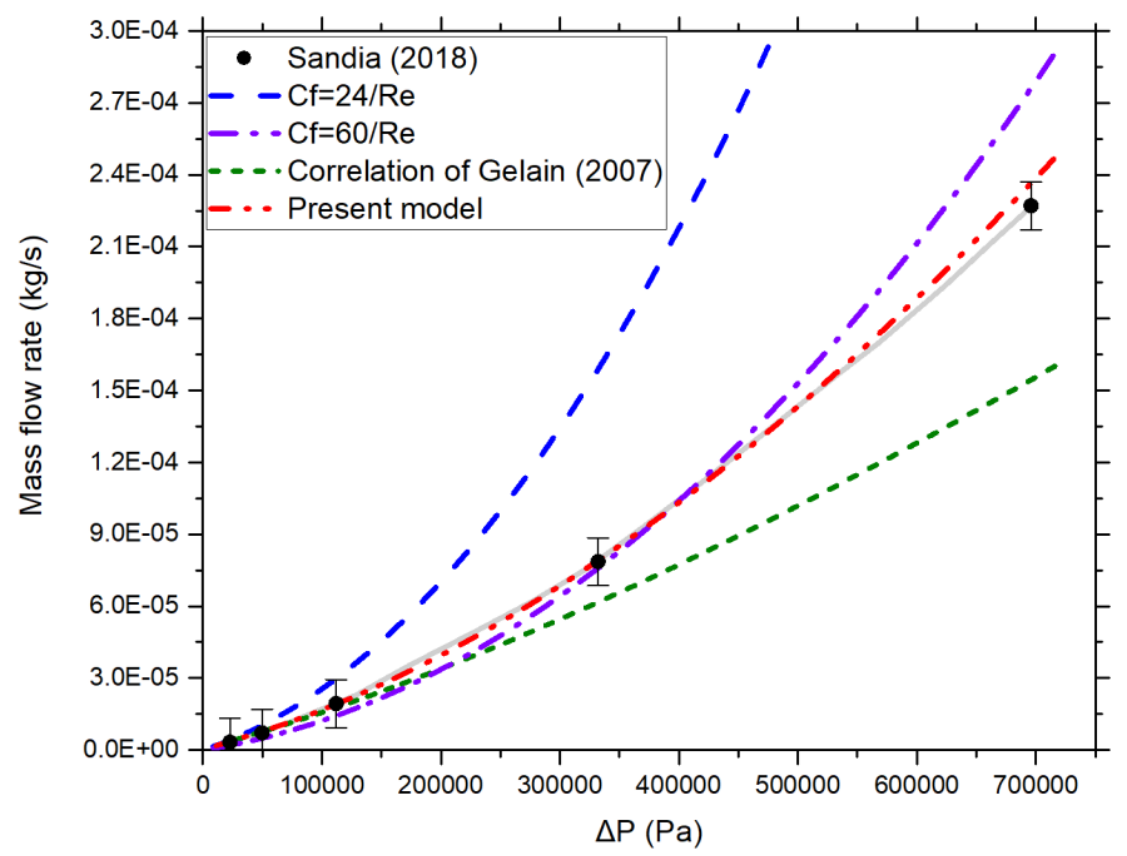

Figure 3. Flow rate vs. pressure differential (pre-aerosol measurements). 
The depressurization equation, Eq. (6), was used to predict the mass flow rate over time. For a tank volume of $0.908 \mathrm{~m}^{3}$, the results are shown in Figure 4. Given the simplicity of the depressurization equation, the results are in good agreement with the experimental measurements, although the difference appears to become larger as time progresses. This can be partially attributed to the simplifying assumptions that were made during the derivation of the depressurization equation. Furthermore, the present aerosol model was in good agreement with the experimental measurements, and it correctly predicted the aerosol concentration within the source container (upstream) due to coagulation, as shown in Figure 5. A coagulation constant of $2 \times 10^{-7} \mathrm{~cm}^{3} / \mathrm{s}$ was used.

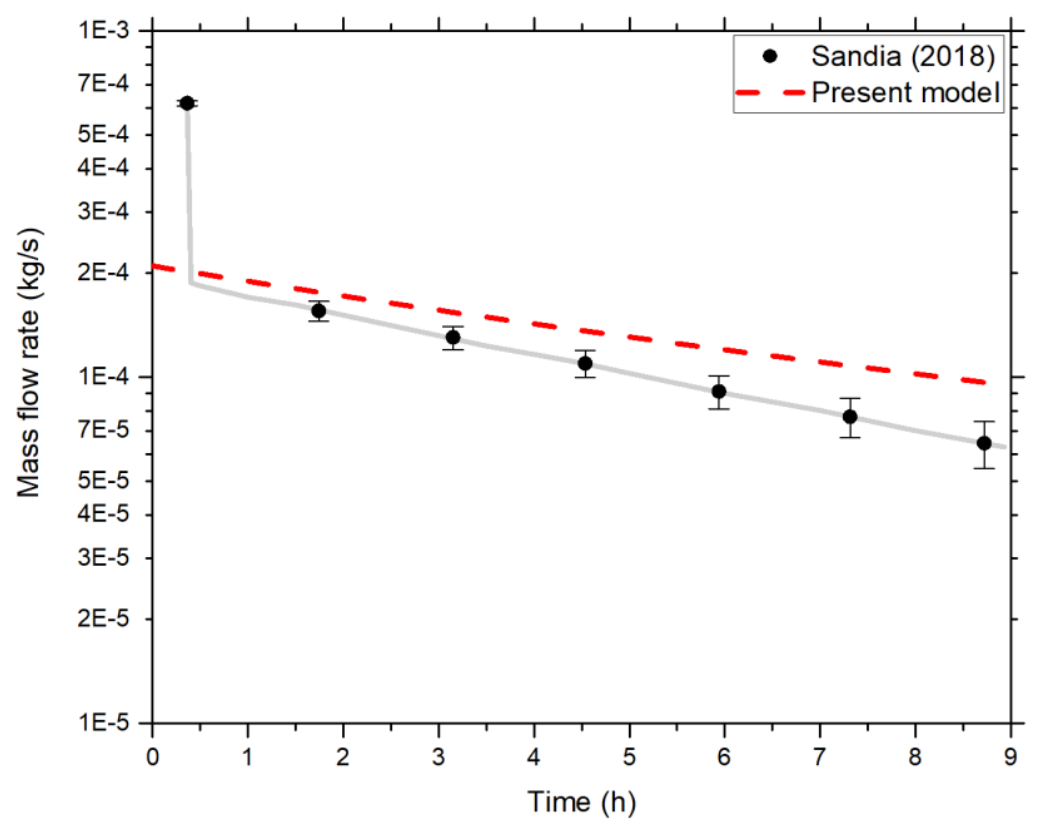

Figure 4. Flow rate vs. time during depressurization.

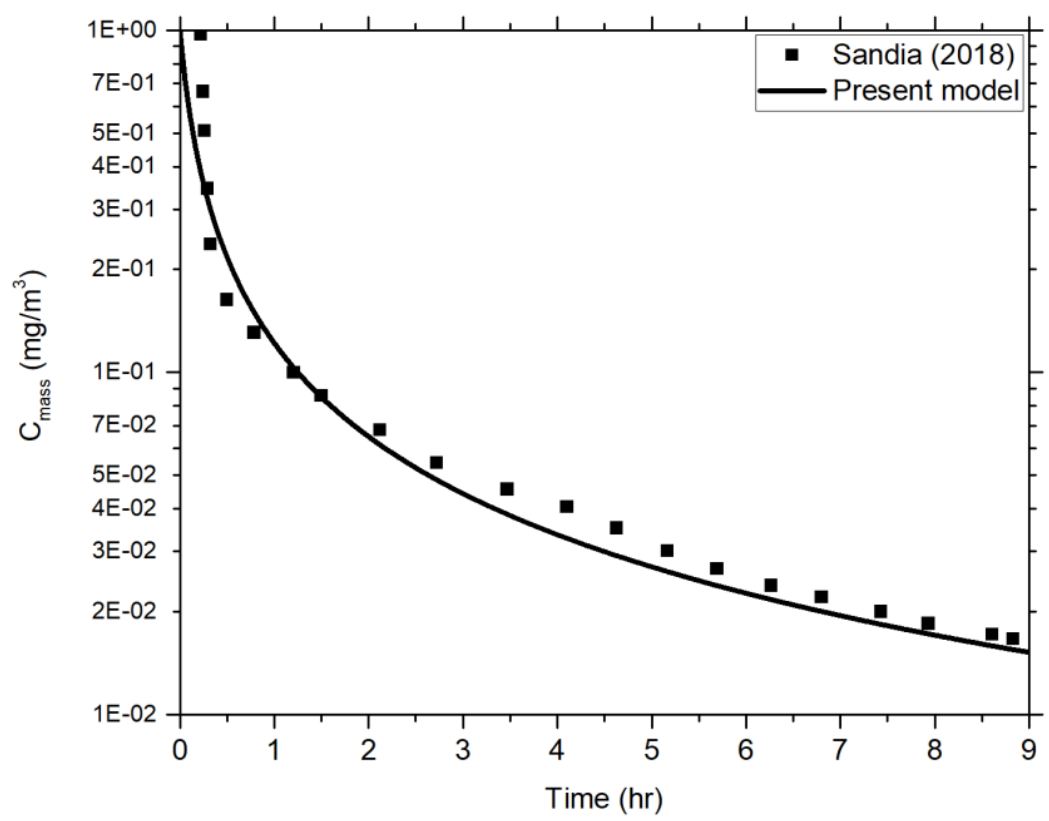

Figure 5. Upstream aerosol mass concentration as a function of time. 


\subsection{Comparison with Liu and Nazaroff (2003)}

Liu and Nazaroff (2003) experimentally studied the penetration of particles through cracks in typical building materials. They studied cracks of well-defined, controlled geometries by machining the materials' samples, but they also created real cracks by breaking a brick. Results from the latter tests were used in the present work to imitate a realistic case. The test conditions refer to a nominal leak path length of $4.5 \mathrm{~cm}$, crack heights of 0.25 and $1 \mathrm{~mm}$, and a pressure difference of $4 \mathrm{~Pa}$. The particle penetration fraction was measured for particle sizes $0.02-7 \mu \mathrm{m}$. Figure 6 shows the penetration fraction of particles for two different crack heights as calculated with the subject numerical model and compares the calculated results with the measured data. The flow was laminar, so only two deposition mechanisms are accounted for in the calculations in this work: namely Brownian diffusion and gravitational settling. The calculated results from the global model of Gelain (2007) are also shown. The following observations were made:

- Generally, both models display similar performances, but the penetration fraction as calculated with Gelain's model (2007) underpredicts when the crack height is $1 \mathrm{~mm}$ and overpredicts when the crack height is $0.25 \mathrm{~mm}$.

- The model of Gelain (2007) goes abruptly to zero for large particles in the $0.25 \mathrm{~mm}$ case. The model developed for the present effort predicts that the penetration fraction will asymptotically reach zero, a behavior more consistent with the measured data.

Overall, it is observed that particles with $d_{p}<0.01 \mu \mathrm{m}$ or $d_{p}>4 \mu \mathrm{m}$ will not penetrate a crack with a height less than $250 \mu \mathrm{m}$. These results agree with the results from Gelain and Vendel (2007).

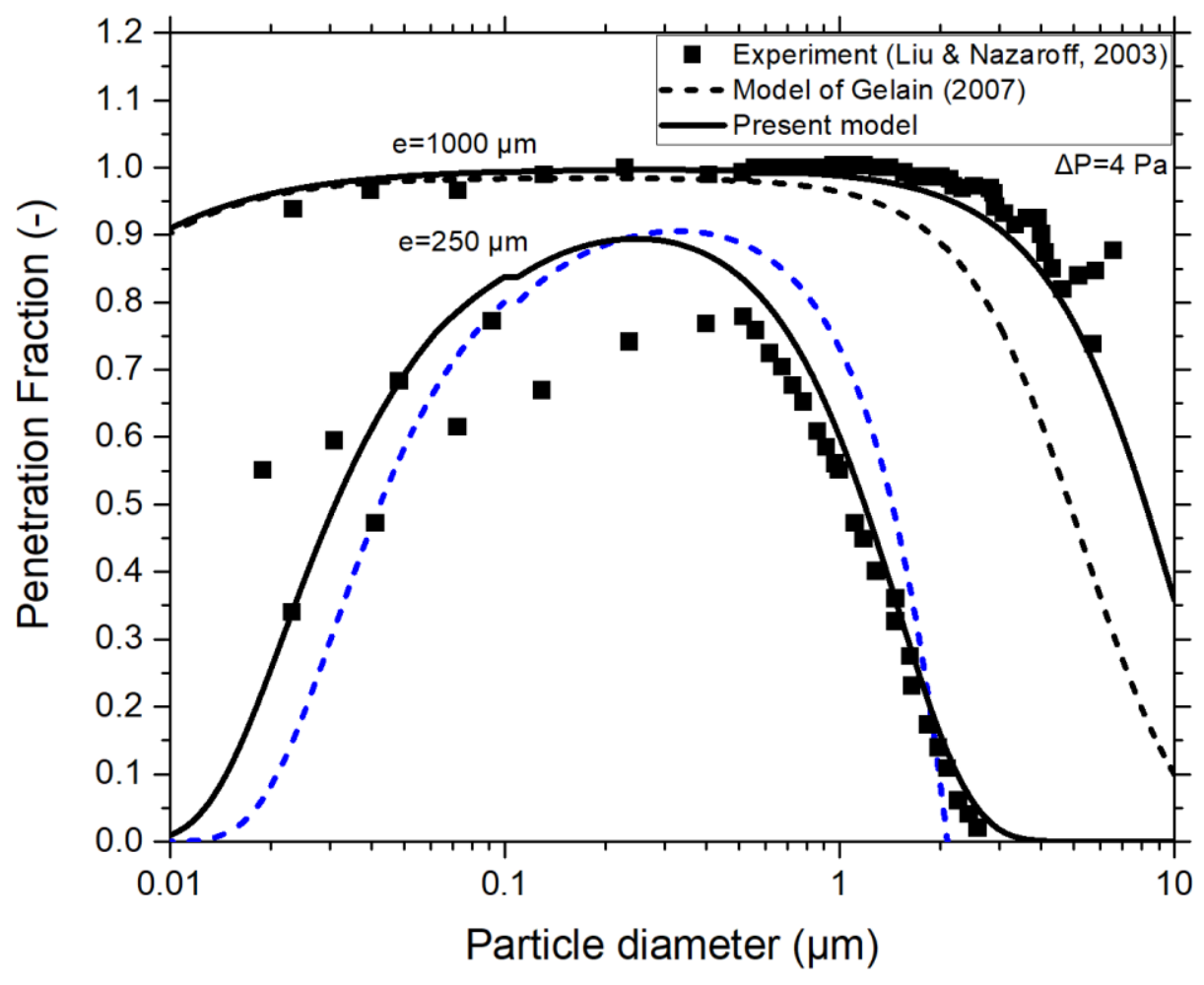

Figure 6. Penetration fraction of particles as a function of particle diameter. 


\subsection{Comparison with Gelain and Vendel (2007)}

The experiments performed by Gelain and Vendel (2007) concern the penetration of particles through a real crack network that was created in a reinforced concrete slab measuring $128 \mathrm{~cm} \times 75 \mathrm{~cm} \times 10 \mathrm{~cm}$. The sample wall was cracked by subjecting it to shear stresses from alternate directions. The tests were performed with monodisperse aerosols with particles between $50 \mathrm{~nm}$ and $4 \mu \mathrm{m}$. The aerosol penetration fraction was measured as a function of the imposed pressure difference across the concrete slab as a function of the flowrate leaking through the crack network. With coarse particles of $4 \mu \mathrm{m}$, the aerosol was completely trapped in the cracks. The results for the $1 \mu \mathrm{m}$ aerosol diameter have shown a partial retention. Figures 7 and 8 show the penetration fraction of particles as calculated with the model developed for this effort, and they compare the calculated results with the measured data.

The present model gives satisfactory results when compared with the experimental measurements of Gelain and Vendel, and it is also in close agreement with their model. Generally, both models display similar performances. The present model gives a more realistic prediction for low flow rates. Gelain's model (2007) predicts values higher than 1.0, while the model developed for this work predicts that the penetration fraction will asymptotically reach 1.0, a behavior which is more consistent with the measured data. Particles of several microns can hardly penetrate through cracks because of the highly efficient removal of such particles by interaction deposition or gravitational settling.

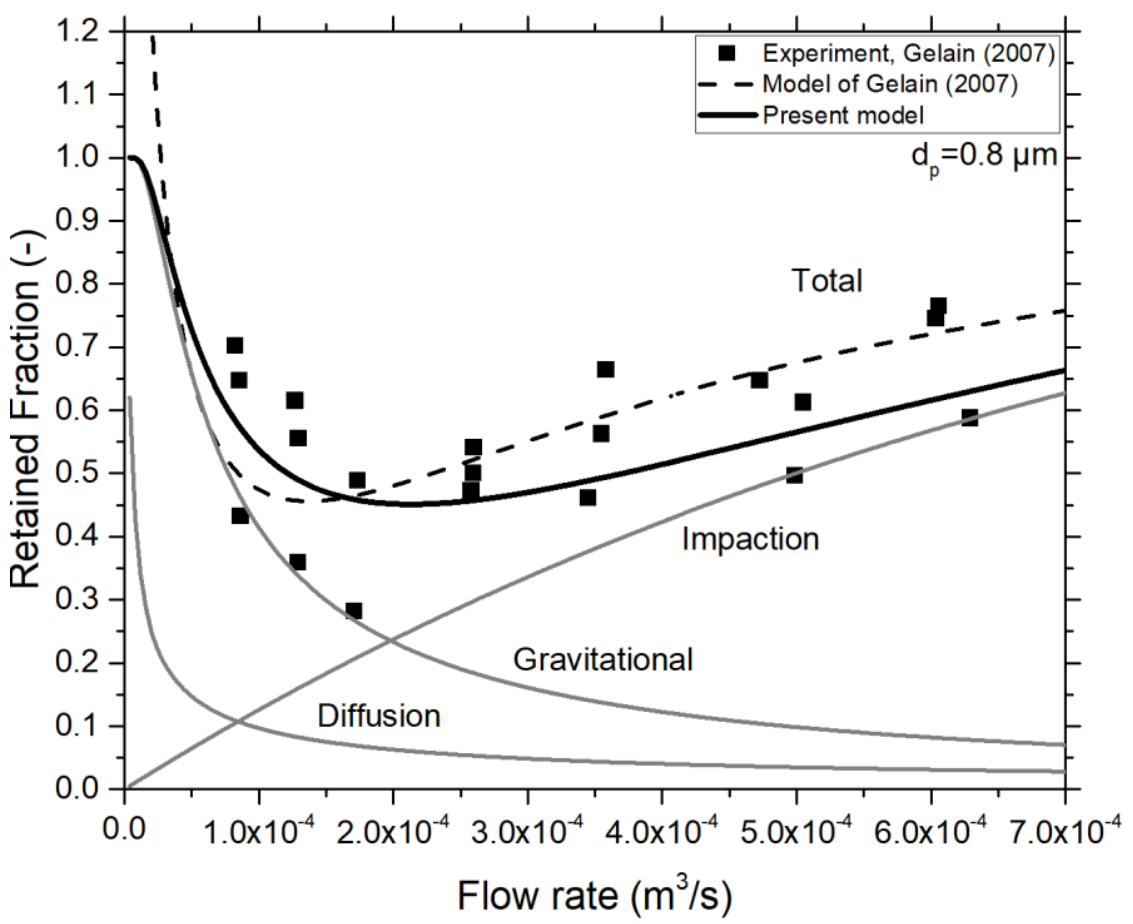

Figure 7. Deposition fractions for particles with an aerodynamic diameter of $0.8 \mu \mathrm{m}$. 


\section{A Phenomenological Model for the Transport and Plugging of Aerosol Through Stress Corrosion Cracks}

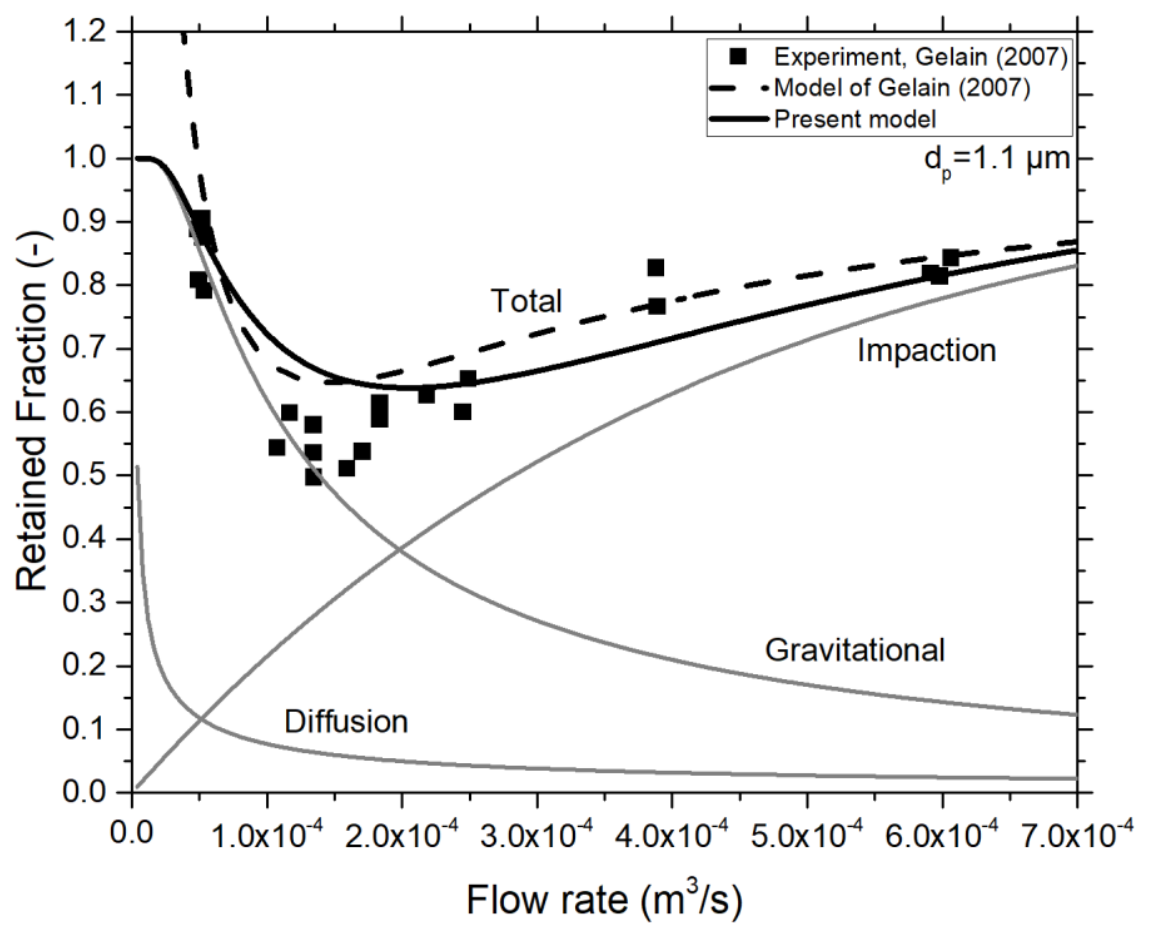

Figure 8. Deposition fractions for particles with an aerodynamic diameter of $1.1 \mu \mathrm{m}$.

\subsection{Comparison with Tian et al. (2017)}

Tian et al. (2017) performed an experimental study of fine aerosol particles $(<0.3 \mu \mathrm{m})$ through capillaries with bore sizes ranging from 5 to $20 \mu \mathrm{m}$ and lengths from 10 to $80 \mathrm{~mm}$. The pressure difference varied from 60 to $450 \mathrm{kPa}$. The results showed that the aerosol penetration efficiency decreased significantly with increased capillary length, but it was identical for capillaries of the same length with different bore sizes. The results also showed that the penetration efficiency correlates more strongly with average flow velocity than with the air leakage rate.

The present aerosol model was in good agreement with the experimental measurements, correctly predicting the aerosol concentration within the source container due to coagulation, as shown in Figure 9. A coagulation constant of $2 \times 10^{-9} \mathrm{~cm}^{3} / \mathrm{s}$ was used. Furthermore, the model results capture the behavior of aerosol penetration efficiency for various bore sizes and flow velocities (Figure 10). 




Figure 9. Aerosol concentration in container as a function of time. The aerosol reduction is due to coagulation.

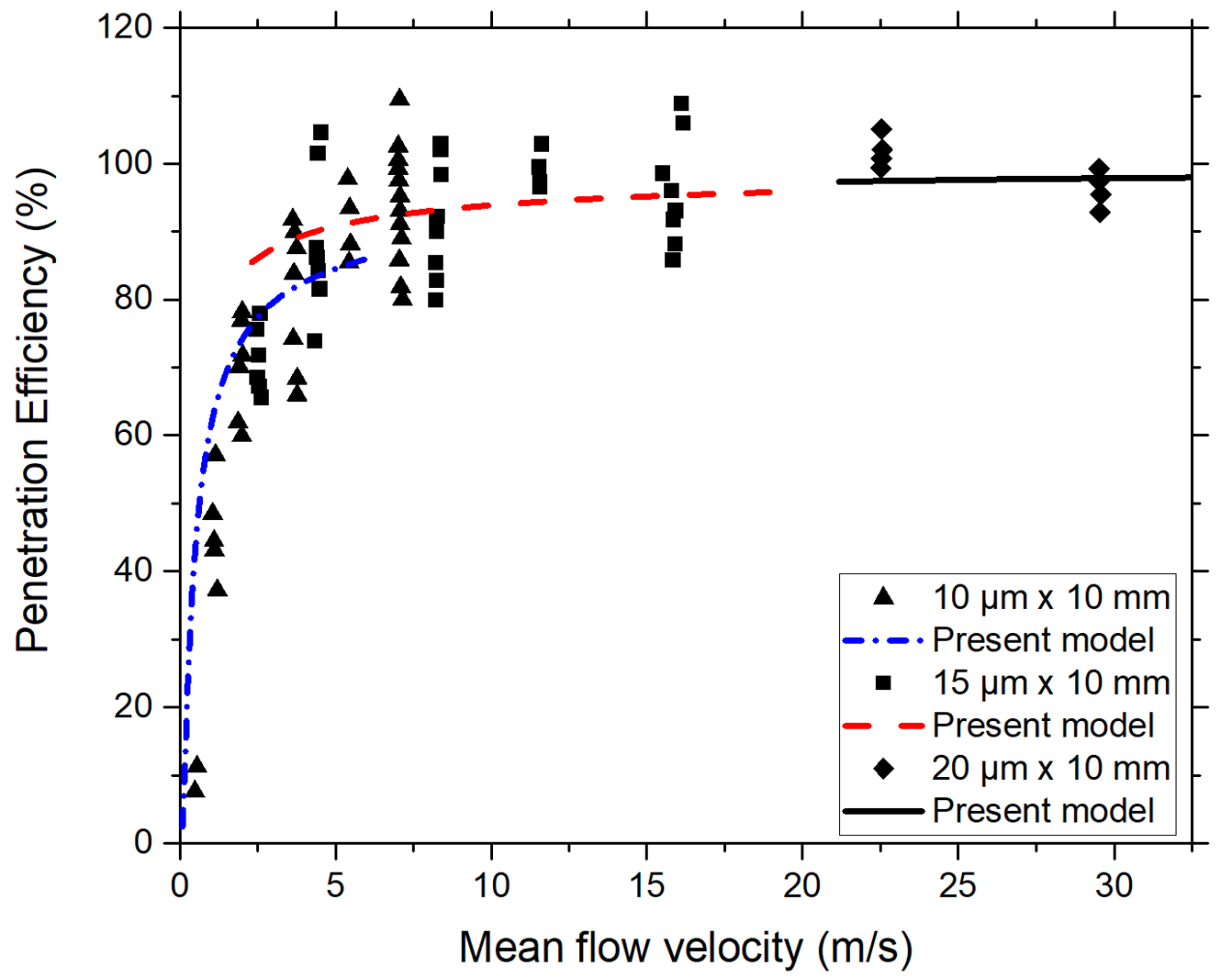

Figure 10. Aerosol penetration efficiency vs. average flow velocity in capillaries. 


\subsection{Flow rate benchmarking}

To evaluate the proposed model's flow rate prediction capabilities, two experiments were used: one in rectangular crack-like geometries [Gelain and Vendel 2007], and one in capillaries of various diameters [Sutter et al. 1979]. The results of the models vs. the experimental measurement results are shown in Figures 11 and 12. The numerical model correctly predicts both the flowrates and Reynolds numbers for various pressure differences in laminar and transition flow regimes. For rectangular geometries, transition to turbulent flow regime starts at $\mathrm{Re}=5-10$. For cylindrical geometries, transition to turbulent flow regime starts at $\operatorname{Re}=400$. This is contrary to the widely used $\operatorname{Re}=2,300-4,000$.

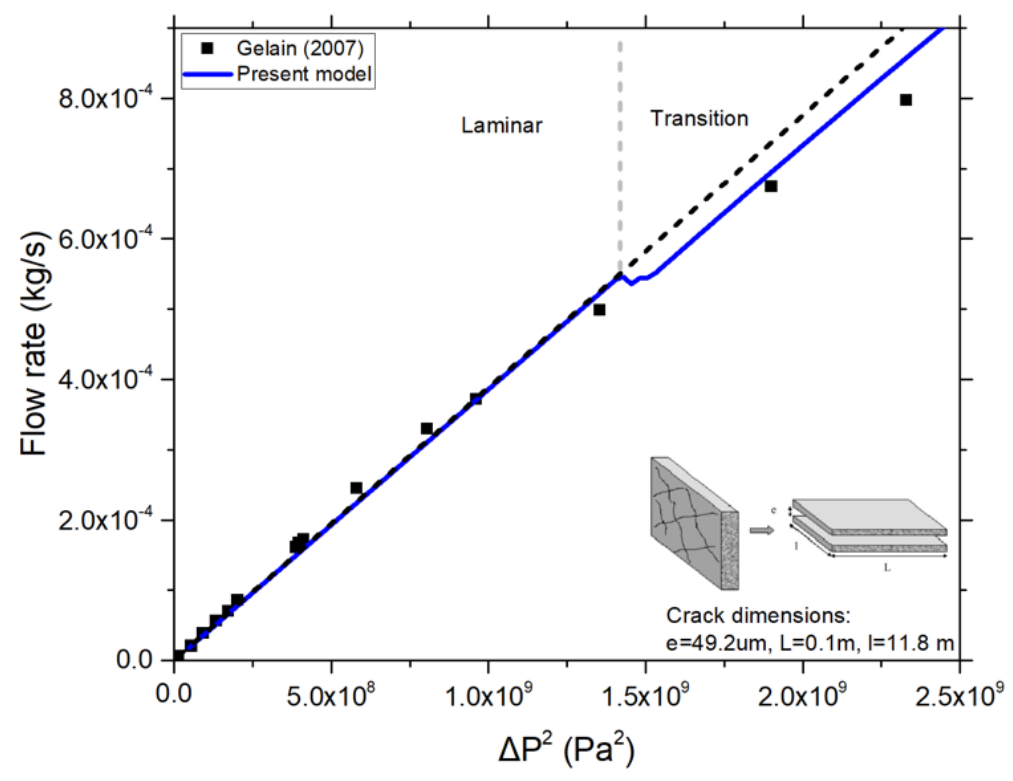

Figure 11. Flow rate vs. pressure difference for rectangular geometry [Gelain and Vendel 2007].

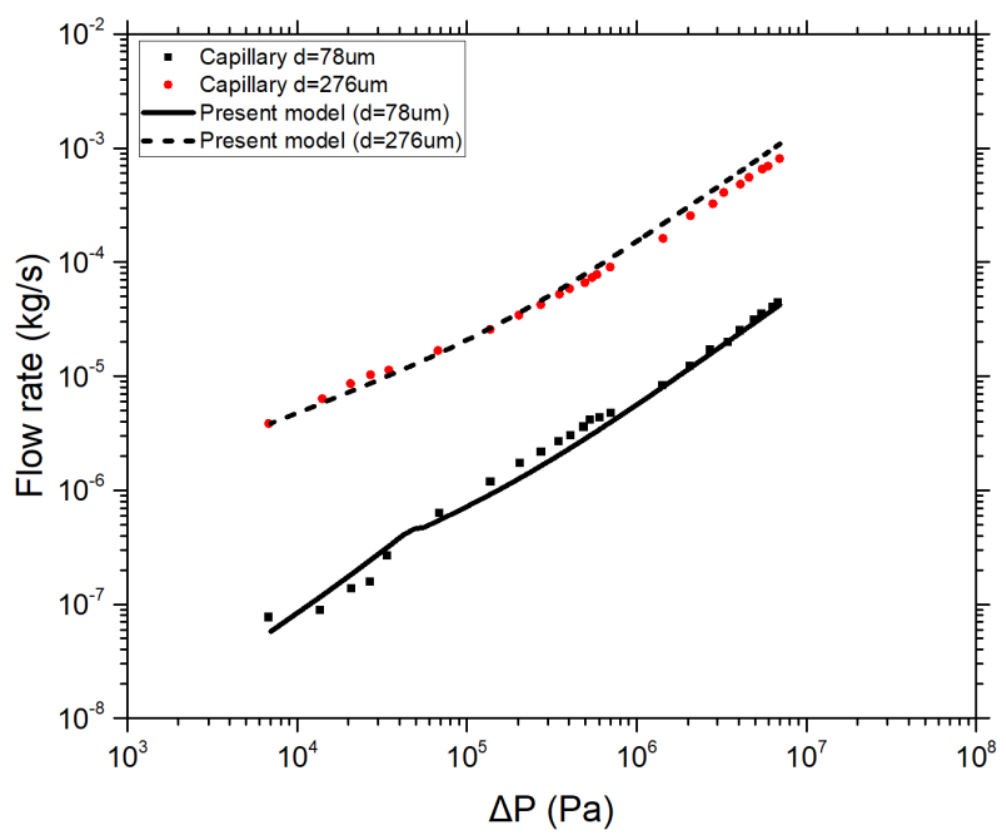

Figure 12. Flow rate vs. pressure difference for cylindrical geometry [Sutter et al. 1979]. 
This page is intentionally left blank. 


\section{A Phenomenological Model for the Transport and Plugging of Aerosol Through Stress Corrosion Cracks}

\section{MODEL APPLICATION EXAMPLE}

This section presents a model application example to demonstrate application of the developed phenomenology to estimate particle penetration through CISCC. In this example, particles are assumed to be spherical with a density of $8 \mathrm{~g} / \mathrm{cm}^{3}$ and with diameters ranging from 0.001 to $10 \mu \mathrm{m}$. The particle density was selected to represent particles with similar densities that may be released within a canister, such as $\mathrm{UO}_{2}$ particles from fuel pellets. A uniform crack geometry was assumed throughout the channel, as well as a smooth inner surface and steady airflow through the crack. Three crack heights (crack opening) were selected: $\mathrm{e}=30 \mu \mathrm{m}, \mathrm{e}=50 \mu \mathrm{m}$, and $\mathrm{e}=100 \mu \mathrm{m}$. Crack width was $10 \mathrm{~mm}$, and crack length was $1.27 \mathrm{~cm}(0.5 \mathrm{in}$.). These dimensions represent real CISCC. In this case, the width of the crack in the third dimension is much larger than the crack opening, so airflow can be reasonably modeled as two dimensional without loss of generality. In real cracks, irregular geometry and surface roughness might increase particle deposition significantly. This issue would be best explored by laboratory-scale experimental studies.

Figure 13 shows particle penetration fractions for a crack height of $30 \mu \mathrm{m}$ and three pressure differences: $\Delta \mathrm{P}=50 \mathrm{~Pa}, 100 \mathrm{~Pa}$, and $200 \mathrm{~Pa}$. These higher pressure differences were selected to help discern the required pressure that will allow significant particle penetration from such a small microcrack. The results suggest that particles with diameters in the range of $0.1-0.5 \mu \mathrm{m}$ have the highest penetration across the entire particle spectrum. This finding is in agreement with earlier experimental results. Larger particles are readily removed in cracks under gravitation settling, and smaller particles are readily removed in cracks under diffusion. The penetration factor becomes negligible for particles with diameters larger than $1 \mu \mathrm{m}$, even when a crack opening is $100 \mu \mathrm{m}$.

For a hypothetical crack height of $50 \mu \mathrm{m}$, the particle penetration fraction is less than $30 \%$. At a crack height of $100 \mu \mathrm{m}$, penetration is less than $90 \%$. This translates to a reduction factor of 3 , although crack height decreased by a factor of 2 . For crack heights less than $30 \mu \mathrm{m}$, penetration is practically zero. This indicates that penetration varies strongly with crack height, and it significantly reduces with smaller crack heights.

Figure 13 shows that a significant pressure difference larger than $50 \mathrm{~Pa}$ is needed for considerable penetration to occur from a $30 \mu \mathrm{m}$ crack. Even when $\Delta \mathrm{P}=200 \mathrm{~Pa}$, penetration is less than $60 \%$. For $\Delta \mathrm{P}=50$ $\mathrm{Pa}$, penetration is less than $20 \%$, and it is practically zero for smaller pressure differences. Figure 14 shows regimes for aerosol transport through CISCC as a function of pressure difference. Highest penetration efficiency is observed for particles in the range of $0.1-0.5 \mu \mathrm{m}$. No particles with diameters $>1$ $\mu \mathrm{m}$ are expected to be released for cracks with an opening displacement (height) less than $100 \mu \mathrm{m}$. Practically no aerosol release is predicted for cracks with opening displacements or heights less than 50 $\mu \mathrm{m}$ when ambient conditions prevail. 


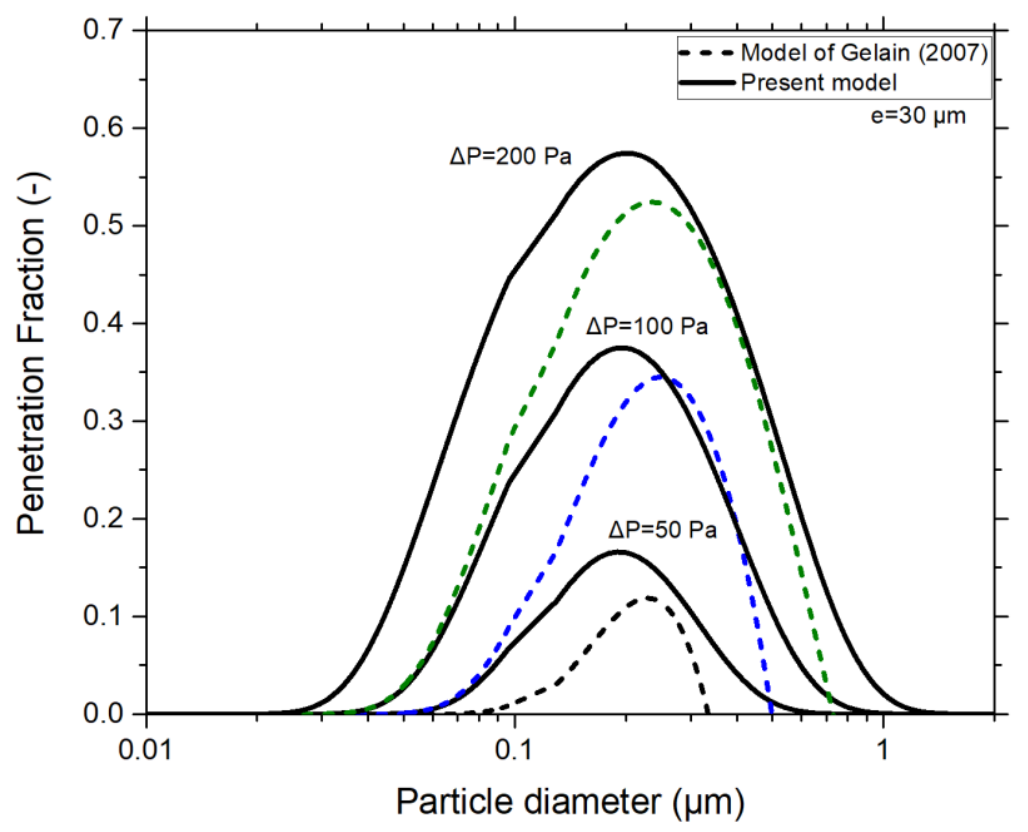

Figure 13. Penetration fraction as a function of particle diameter for crack heights $\mathrm{e}=30 \mu \mathrm{m}$ and $\Delta \mathrm{P}=50 \mathrm{~Pa}, 100 \mathrm{~Pa}$, and $200 \mathrm{~Pa}$.

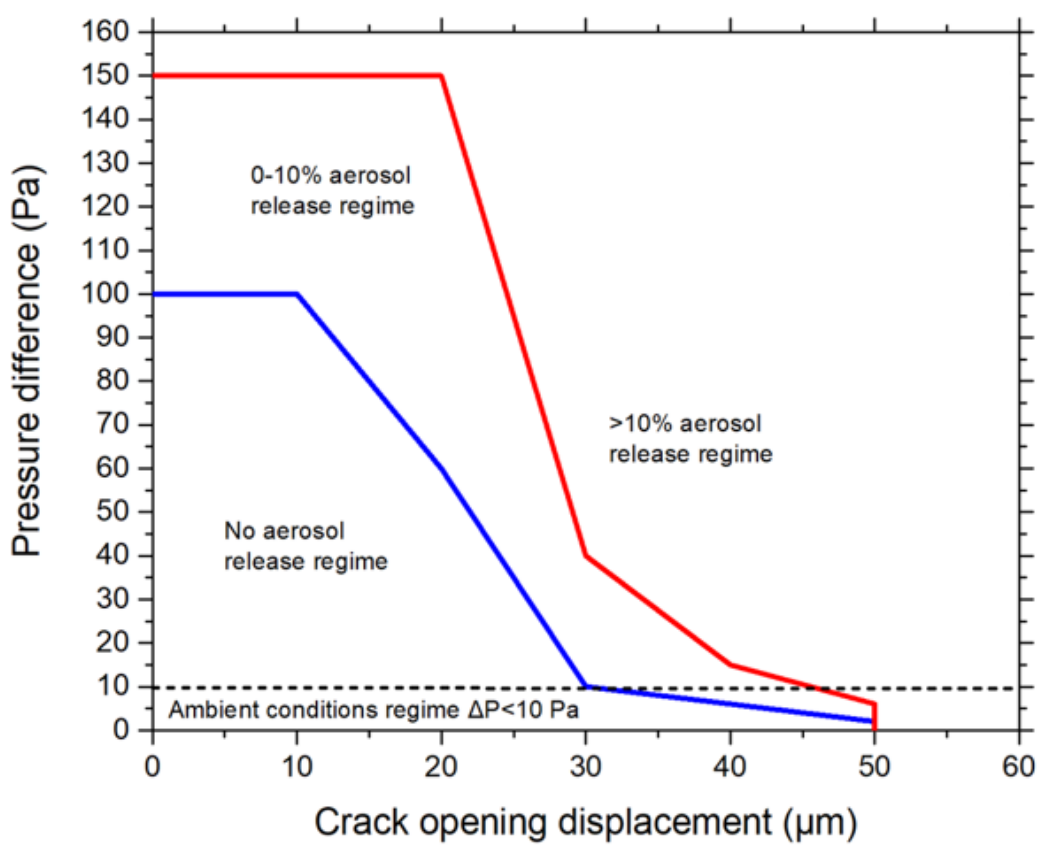

Figure 14. Regimes for aerosol transport through CISCC as a function of pressure difference (Penetration as a function of the particle size spectrum is shown in upper right of figure; Ambient conditions: conditions following canister depressurization). 


\section{A Phenomenological Model for the Transport and Plugging of Aerosol Through Stress Corrosion Cracks}

\section{SUMMARY}

A phenomenological model is currently under development that enables the calculation of aerosol transport and retention in leak paths and that also accounts for plugging formation. The model assumes a one-dimensional flow through a hydraulically equivalent leak path. The description is dynamical, with changing duct geometry due to plugging, and it is also mechanistic. An extensive validation exercise (particle diameters: $0.01-10 \mu \mathrm{m}$ and pressure difference up to $700 \mathrm{kPa}$ ) is in progress based on comparisons with experimental measurements and empirical correlations. The model predictions are in approximate agreement with experimental data and are reasonably representative.

Further progress will require (i) improvements to further refine the model and (ii) additional experimental studies for model validation. Experiments should include:

- Determination of flow rates for various pressures to provide insight on flow regimes and to develop friction factor correlations in a microchannel

- Measurements of aerosol concentration in a canister, including polydisperse aerosol, to better understand aerosol reduction processes such a coagulation and deposition and for model validation

- Tests that result in complete plugging of a microchannel to better understand aerosol plugging conditions and for model validation

Advances in this area hold the promise of improving the accuracy of consequence assessments and reducing the uncertainty of radiological consequence predictive analyses by taking the filtering effect of leak path aerosol deposition and plugging into account in the source term. 
This page is intentionally left blank. 


\section{REFERENCES}

EPRI 2017. Dry Cask Storage Welded Stainless Steel Canister Breach Consequence Analysis Scoping Study. Report No. 3002008192. Palo Alto, CA: EPRI.

Chatzidakis, S. 2018a. Literature Review and Data for Aerosol Model Development. Prepared for DOE Spent Fuel and Waste Science and Technology Program. ORNL Report No. ORNL/SPR-2018/1217, Revision 0.

Chatzidakis, S. 2018b. SCC Aerosol Transport Model Summary Report. Prepared for DOE, Spent Fuel and Waste Science and Technology Program. ORNL Report No. ORNL/SPR-2018/1072, Revision 0.

Chatzidakis, S. 2019. Summary of Aerosol Transport Model Validation. Prepared for DOE, Spent Fuel and Waste Science and Technology Program. ORNL Report No. ORNL/SPR-2018/1197, Revision 0.

Chatzidakis, S. and Scaglione, J. 2019. "A Mechanistic Description of Aerosol Transport and Deposition in Stress Corrosion Cracks," Proceedings of Global/TopFuel Conference 2019, pp. 1033-1039, September 22-27, Seattle, WA.

Gelain, T. and Vendel, J. 2007. "Research Works on Contamination Transfers through Cracked Concrete Walls." Nucl. Eng. Des. 238, 1159-1165.

Liu, D. and Nazaroff, W. W. 2003. "Particle Penetration through Building Cracks." Aerosol Sci. Technol. $37,565-573$.

Mitrakos, D. et al. 2008. "A Simple Mechanistic Model for Particle Penetration and Plugging in Tubes and Cracks." Nucl. Eng. and Des. 238, 3370-3378.

Sandia 2018. Measurement of Particulate Retention in Microchannel Flows. Prepared for DOE Spent Fuel and Waste Science and Technology Program. Durbin, S. (Sandia). Report No. SAND2018-10522 R, Revision 0.

SKI (Swedish Nuclear Power Inspectorate) 2006. Crack Characterization for In-Service Inspection Planning - An Update.

Sutter, S. et al. 1979. Depleted Uranium Dioxide Powder Flow through Very Small Openings. NUREG/CR-1099, PNL-3177, Pacific Northwest Laboratory, Richland, WA.

Tian, M. et al., 2017. "Experimental Study on the Penetration Efficiency of Fine Aerosols in Thin Capillaries." J. Aerosol Sci. 111, 26-35.

Williams, M. M. R. 1994. "Particle Deposition and Plugging in Tubes and Cracks (with Special Reference to Fission Product Retention)." Prog. Nucl. Energy 28, 1-60. 
This page is intentionally left blank. 